\title{
Aksillêre temperatuur vergelyk met timpaniese membraan temperatuur in kinders
}

\section{Axillary temperature compared to tympanic membrane temperature in children.}

\author{
G Greyling \\ M.B.Ch.B., M.Fam.Med. \\ Departement Huisartskunde \\ Fakulteit Gesondheidswetenskappe \\ Universiteit van die Oranje Vrystaat \\ \& \\ MJ Viljoen \\ D.Soc.Sc. \\ Skool vir Verpleegkunde \\ Fakulteit Gesondheidswetenskappe \\ Universiteit van die Oranje Vrystaat \\ \& \\ G Joubert \\ B.A., M.Sc. \\ Departement Biostatistiek \\ Fakulteit Gesondheidswetenskappe \\ Universiteit van die Oranje Vrystaat
}

\section{"Pasiënttevredenheid, spoed en} gemak waarmee die temperatuur gemeet word, die akkuraatheid van meting sowel as die kosteeffektiwiteit daarvan, speel egter 'n rol wanneer 'n geskikte metode vir temperatuurmeting gekies word."

\section{Opsomming}

Die doel van die studie was om aksillêre temperatuur op drie, ses en nege minute by ' $n$ honderd kinders tussen die ouderdomme van een en twaalf jaar, wat onewekansig doelgerig geselekteer is, te meet, en te vergelyk met die timpaniese membraan temperatuur (goue standaard) wat terselfdertyd by die proefpersone gemeet is. Die resultate word beskryf deur sensitiwiteit, spesifisiteit, grense van ooreenstemming, en voorspellingswaardes.

Uit van die bevindinge van die navorsing, blyk dit dat die aksillêre temperatuurlesing toeneem na meting van drie, ses en nege minute. By slegs $9 \%$ van die proefpersone is ' $n$ maksimum temperatuurlesing na drie minute bereik, by $25 \%$ na ses minute en by $66 \%$ na nege minute.

Uit die bevindinge blyk dit dat die reikwydtes wat gebruik word, die sensitiwiteit van die meting beïnvloed, en dit wil voorkom of die reikwydte 35,5 tot $37,2^{\circ} \mathrm{C}$ die beste reikwydte is om pireksie te meet in die ouderdomsgroep een tot 12 jaar. Die 9 minute meting het dan die hoogste sensitiwiteit. Die spesifisiteit van meting met hierdie reikwydte is egter laer.

Die gevolgtrekking word gemaak dat aksillêre temperatuurmeting ' $n$ aanvaarbare metode, met sekere voorbehoude is, om as siftingsmetode te gebruik vir pireksie in noodgevalle afdelings of klinieke.

\section{Summary}

The purpose of the study was to measure the axillary temperature at three, six and nine minutes in a hundred children between the ages of one and twelve years who were selected in a non-random deliberate way, and to compare the measurements with the tympanic membrane temperature (golden standard) which was measured in the test persons at the same time. The results were described by sensitivity, specificity, limits of agreement, and predictive values.

From some of the findings of the research it is apparent that the axillary temperature reading increased after measurement of three, six and nine minutes. A maximum temperature reading was reached after three minutes in only $9 \%$ of the test persons, in $25 \%$ after six minutes and in $66 \%$ after nine minutes. From the findings it is clear that the ranges that were used influenced the sensitivity of the measurements, and it would appear that the range $35,5^{\circ} \mathrm{C}$ to $37,2^{\circ} \mathrm{C}$ was the best range to measure pyrexia in the age group one to 12 years. The 9 minute measurement then had the highest sensitivity. However, the specificity of measurement in this range was lower. The conclusion was drawn that axillary temperature measurement is an acceptable method, with certain reservations, to use as screening method for pyrexia in emergency divisions or clinics. 


\section{Inleiding en probleemstelling}

Die kliniese belang van die vasstelling van pasiënte se liggaamstemperatuur met aanmelding by ' $n$ gesondheidsdiensinstansie, as deel van data wat tydens pasiëntondersoek verkry moet word, moet nie onderskat word in tye waar die gebruik van hoë tegnologie die norm geword het nie.

' $n$ Verandering in liggaamstemperatuur is ' $n$ waarskuwingsteken dat die hittebalans in die liggaam versteur is. Deur die waarskuwingsteken betyds te herken, kan die onderliggende kliniese probleem verder ondersoek en hanteer word. Die doel van temperatuurmeting is dan ook om die liggaamskerntemperatuur so akkuraat as moontlik te bepaal.

Pasiënttevredenheid, spoed en gemak waarmee die temperatuur gemeet word, die akkuraatheid van meting sowel as die koste-effektiwiteit daarvan, speel egter ' $n$ rol wanneer ' $n$ geskikte metode vir temperatuurmeting gekies word.

Liggaamstemperatuur en die regulering daarvan word deur verskeie faktore beinvloed en dit opsigself beïnvloed die meting van liggaamstemperatuur. Faktore wat liggaamstemperatuur beinvloed is ouderdom, sirkadiese ritmes ${ }^{1}$, oefening, hormone, stres of spanning en omgewing.

Die foutiewe meet van liggaamstemperatuur kan onder andere die volgende probleme tot gevolg hê:

- Gesondheidsorgwerkers kan sodoende mislei word en verkeerde diagnoses kan gemaak word.

- Pasiënte met hoë liggaamstemperature kan ontslaan word, sonder dat ' $n$ antipiretikum toegedien is en komplikasies soos koorskonvulsies kan veral vir kinders nadelig wees.

- Gesondheidsorgwerkers kan vermoed dat ' $n$ kind se aanvoelbare temperatuur nie met die gemete waarde korreleer nie en die temperatuurmeting moet gevolglik herhaal word, wat ongerief vir die pasiënt kan veroorsaak en nie goeie tydsbenutting is nie.

In Universitashospitaal noodgevalle en Heidedal pediatriese kliniek is dit algemene beleid dat verpleegkundiges liggaamstemperatuur by pasiënte meet, voordat dokters pasiënte ondersoek. Orale en rektale temperatuurmeting het oor die algemeen in onbruik verval. By kinders en die meeste volwassenes word die temperatuur vir \pm 3 minute in die oksel gemeet. Orale temperatuur word net in spesiale gevalle gemeet.

Aksillêre temperatuurmeting se akkuraatheid word veral beinvloed deur die tydsduur wat die termometer in die oksel gehou word en deur die temperatuur reikwydtes wat gebruik word om pireksie te definieer. (Erickson \& Woo, 1994; Davis, 1993). Aksillêre temperatuur word al oor ' $n$ lang tydperk met ' $n$ kwik-in-glas termometer gemeet.

Die akkuraatheid van die kwik-in-glas termometer, word beïnvloed deur die akkuraatheid van kalibrasie en kwaliteit van vervaardiging. Baie kwik-in-glas termometers raak onakkuraat binne die eerste jaar van gebruik as gevolg van produksiefoute (Abbey, Anderson \& Close, 1978). Die voordele van die kwikin-glas termometer is onder andere: maklik bekombaar, goedkoop en kan sublinguaal, rektaal of aksillêr gebruik word. Die nadele sluit in: breek maklik, as dit breek, kan beserings

1 Liggaamstemperatuur wissel normaalweg deur die dag tot met 1 graad Celsius. Die hoogste liggaamstemperatuur word bereik tussen $20 \mathrm{~h} 00$ en $24 \mathrm{hO0}$, en die laagste tussen 04h00 en 06h00. of kwikvergiftiging plaasvind, neem langer as ander metodes om ' $n$ temperatuurlesing te verkry, breek baie maklik, akkuraatheid word betwyfel, bakteriële kontaminasie en kruisinfeksie kan maklik plaasvind (Davis, 1993).

Die voordele van aksillêre temperatuurmeting sluit in:

- 'n Veilige en nie ingrypende metode.

- Het 'n lae risiko vir bakteriële besoedeling en kruiskontaminasie.

- Veroorsaak min emosionele en fisieke ongerief by ouer kinders en volwassenes.

- Die kwik-in-glas termometer wat gebruik word, is goedkoop en maklik bekombaar (Alexander, Fawcett \& Runciman, 1994).

Die nadele van aksillêre temperatuurmeting sluit in

- Dit is nie sensitief om pireksie te meet nie (Ogrien, 1990; Kresch, 1984; Weisse, Reagan, Baule \& France, 1991).

- Dit gee nie ' $n$ goeie indikasie van kerntemperatuur nie, en moet as perifere temperatuur geag word (Kresch, 1984; Heidenreich \& Guiffre, 1990).

- Daar is baie kontroversie aangaande die betroubaarheid en akkuraatheid van aksillêre temperatuurmeting, asook oor die tydsduur van meting (Morley, Thornton, Cole \& Henson, 1991; Bliss-Holtz, 1989, Haddock, Vincint \& Merrow, 1986; Kunnel, O'Brien, Munro, Medoff \& Cooper, 1988; Mayfield, Bratia, Nakamurak, Rios \& Bell, 1984; Anognostakis, Matsaniotis, Grafakos \& Sarafidou, 1993; Eloff, Meier \& Miller, 1974).

- Verdamping van sweet in die oksel, asook swak velkontak met die termometer dra by tot onakkurate lesings (Boylan \& Brown, 1985)

- As die termometer vir langer as drie tot vyf minute in die oksel gehou word, kan dit baie ongemak by klein kinders en babas veroorsaak, wat verder kan lei tot onakkurate lesings.

- Om die termometer vir nege tot elf minute in die oksel te hou, is onprakties en tydrowend.

Timpaniese membraan temperatuurmeting (TMTM) is ' $n$ betreklik nuwe en onbekende metode van temperatuurmeting, en meet die infrarooi uitstraling van die timpaniese membraan. Dit is egter ' $n$ vinnige, veilige en baie gerieflike metode om ' $n$ weergawe van kerntemperatuur te verkry (Kenney, Fortenberry, Surratt, Ribbeck \& Thomas, 1990; Barlett, 1996)

Timpaniese membraan temperatuur word met ' $n$ ototermometer wat in die oorkanaal geplaas word, gemeet. Die ototermometer bestaan uit die otoskoop (infrarooi lens), elektroniese sirkelbaan mikroprosesseerder, wat die temperatuurlesing gee en die handstuk (Tomotsu Shiwozaki, Nobert \& Frederick, 1988)

Die vroeë ototermometers het aan die timpaniese membraan geraak. Weens die gevaar van timpaniese perforasie, word die metode tans net vir navorsing of tydens narkose gebruik. Sedert 1986 het verskeie soorte ototermometers op die mark gekom wat nie kontak met die timpaniese membraan maak nie, maar die uitstraling van infrarooi strale vanaf die timpaniese membraan meet. Sodra die otoskoop met die infrarooi lens in die oorkanaal geplaas is, word die infrarooi strale geabsorbeer vanuit die rigting waarop die otoskoop gerig is.

Die oorkanaal het gewoonlik ' $\mathrm{S}$ v vorm by groter kinders en volwassenes, is ongeveer drie sentimeter lank en bestaan uit ' $n$ benige binnedeel en ' $n$ buitedeel van kraakbeen, die pinna Traksie aan die pinna lateraal- en dan posteriorwaarts maak die kraakbeenkanaal reguit en verbeter die visie op die timpaniese membraan (Pransky, 1991)

In studies by kinders (Freed \& Fraley, 1992; Kelly \& Alexander, 


\begin{tabular}{|c|c|}
\hline VOORDELE & NADELE \\
\hline $\begin{array}{l}\text { 'n Vinnige metode wat ongeveer twee tot vyf sekondes neem. } \\
\text { Dit spaar baie verpleegtyd (Pransky, 1991). }\end{array}$ & $\begin{array}{l}\text { Die ototermometer varieer tussen gemiddeld bekostigbaar } \\
\text { tot baie duur. }\end{array}$ \\
\hline $\begin{array}{l}\text { Baie higiënies met lae risiko vir kruiskontaminasie omdat dit } \\
\text { nie met die mukusmembraan kontak maak nie. }\end{array}$ & Die ototermometer is nie orals maklik bekombaar nie. \\
\hline $\begin{array}{l}\text { Veroorsaak min ongemak en spanning vir pasiënte (Barber } \\
\text { \& Kimon, 1989). }\end{array}$ & $\begin{array}{l}\text { Die ototermometer se oorstuk pas nie in ' } n \text { klein baba se } \\
\text { oorkaanaal nie en daarom is die ondersoek onbetroubaar } \\
\text { in kinders kleiner as ' } n \text { jaar (Davis, 1993; Terndrup \& Milewski, } \\
\text { 1991). }\end{array}$ \\
\hline $\begin{array}{l}\text { Die ototermometer is in die vorm van ' } n \text { telefoon en kinders } \\
\text { vind die ondersoek oor die algemeen baie aangenaam (Al- } \\
\text { exander \& Kelly, 1991). }\end{array}$ & $\begin{array}{l}\text { Omdat die ototermometer in verskillende modusse gebruik } \\
\text { kan word, kan die interpretasie van lesings verwarrend en } \\
\text { onbetroubaar wees (Kenney et al., 1990; Ros, 1989). }\end{array}$ \\
\hline $\begin{array}{l}\text { Die TMT is 'n goeie indikator van ware kerntemperatuur, soos } \\
\text { blyk uit studies wat gedoen is (Rhoads \& Grandner, 1988; } \\
\text { Muma, Treloar, Wurmlinger, Peterson \& Vitae, 1991; Kenney } \\
\text { et al., 1990; Kelly \& Alexander, 1991; Nierman, 1991). }\end{array}$ & $\begin{array}{l}\text { Die vorm en grootte van die oorkanaal beinvloed die } \\
\text { betroubaarheid van die temperatuurmeting (Davis, 1993; } \\
\text { Terndrup \& Milewski, 1991). }\end{array}$ \\
\hline
\end{tabular}

1991; Shenep, Adair \& Hushes, 1991; Terndrup \& Rajk, 1992) en volwassenes (Guthrie \& Kreuneve, 1992) is bevind dat die timpaniese membraantemperatuur $0,1^{\circ} \mathrm{C}$ tot $0,2^{\circ} \mathrm{C}$ hoër is wanneer die oorkraakbeen gemanipuleer is. In ander studies was die temperatuurlesing laer (Erickson \& Meyer, 1992) of onveranderd (Erickson \& Woo, 1994; Davis, 1993).

Selfs indien die ototermometer korrek geposisioneer is, is die temperatuurlesing wat gemeet word, ' $n$ gemiddeld tussen die timpaniese membraan en die omliggende weefsel of oorkanaal. Die temperatuur wat gemeet word is daarom dikwels laer as die ware timpaniese membraan temperatuur (Fraden \& Lackey, 1991).

Die tipe modus waarin die ototermometer gestel is, bepaal watter omkeringsfaktor by die basiese temperatuurmeting gevoeg word. Die tipe modus wat gebruik word, bepaal ook die normale reikwydtes van liggaamstemperatuur. Byvoorbeeld, kerntemperatuur is $36^{\circ} \mathrm{C}$ tot $37^{\circ} \mathrm{C}$, terwyl die van aksillêre, rektale en veloppervlaktemperature se reikwydtes weer anders is.

Met die meting van timpaniese membraan temperatuur, kan die ototermometer in een van die volgende modusse gebruik word:

- Kerntemperatuur,

- Aksillêre temperatuur,

- Veltemperatuur, en

- Rektale temperatuur.

Sommige ototermometers kan die veloppervlakstemperatuur meet indien dit in die modus gestel word. Die meet van veltemperatuur is baie nuttig in inflammatoriese toestande, brandwonde en veloorplantings.

Die timpaniese membraan deel dieselfde bloedvoorsiening as die hipotalamus en derhalwe sal die timpaniese membraan temperatuur vroeg verander as die hipotalamus se stelpunt verander (Barlett, 1996).

Kerntemperatuur is ' $n$ denkbeeldige parameter omdat dit die temperatuur van die hipotalamus bepaal, as dit gemeet sou kon word. Die timpaniese membraan het dus die liggaam se hoogste temperatuur naas die hipotalamus. Die aanname kan dus gemaak word dat die timpaniese membraan temperatuur die ware kerntemperatuur verteenwoordig (Freed \& Fraley, 1992; Kenney et.al., 1990).

Ander voor- en nadele van TMTM word in Tabel 1 uiteengesit.

\section{Die doelstellings van die}

\section{navorsing}

Om te bepaal hoe aksillêre temperatuurlesings onderskeidelik verskil na drie, ses en nege minute metings.

Om te bepaal hoe akkuraat aksillêre temperatuurmeting in vergelyking met timpaniese membraan temperatuurmeting is.

\section{Definisies}

Vir die doeleindes van hierdie studie is die onderstaande konsepte as volg gedefinieer.

Liggaamstemperatuur verteenwoordig die balans tussen liggaamshitteproduksie en -verlies. Daar word na twee tipes liggaamstemperature, naamlik kerntemperatuur en oppervlaktemperatuur, verwys (Alexander, M.F., Fawcett, J.N. \& Runciman P.J. 1994; Henry M. \& Adam M.D. 1996).

Kerntemperatuur is die temperatuur van die diep weefsel of organe van die liggaam soos die brein, toraks, abdominaleen pelviese holte, en bly redelik konstant (Alexander et al., 1994).

Oppervlaktemperatuur is die temperatuur van die vel, subkutane weefsel, slymvlies en vet. Oppervlaktemperatuur varieer baie in ooreenstemming met omgewingstemperatuur (Alexander et al., 1994).

Aksillêre temperatuur is liggaamstemperatuur gemeet in die oksel met ' $n$ kwik of elektroniese termometer, en kan as oppervlakstemperatuur beskou word. Dit word vinnig deur die omgewingstemperatuur beïnvloed (Alexander et al., 1994). 
Timpaniese membraantemperatuur (TMT) is liggaamstemperatuur gemeet in die oorkanaal met ' $n$ ototermometer. ' $n$ Ototermometer meet infrarooistrale wat vanaf die timpaniese membraan uitstraal en registreer dit as ' $n$ temperatuurlesing. TMT is verteenwoordigend van kerntemperatuur (Summers, 1991; Brinnel \& Cabana, 1989; Ros, 1989).

Pireksie is ' $n$ verhoging in liggaamstemperatuur in respons tot die verhoging van die stelpuntwaarde van die hipotalamus. (Dit kom voor as gevolg van ' $n$ infeksie of enige ander versteuring in die liggaamsverdedigingsmeganisme.) (Alexander et al., 1994; Henry \& Adam, 1996)

Goue standaard is die metode wat beskou word as die een wat die mees akkurate temperatuurmeting verskaf.

\section{Navorsingsmetodologie}

Die studie is by Heidedal polikliniek en Universitas noodgevalle uitgevoer oor 'n tydperk van drie weke. 'n Onewekansige doelgerigte steekproef is volgens in- en uitsluitingskriteria geselekteer. Die steekproefgrootte was 100 kinders.

Babas en kinders vanaf die ouderdom een tot twaalf jaar is vir insluiting in die studie oorweeg. Babas en kinders op wie die onderstaande uitsluitingskriteria van toepassing was, het nie as proefpersone gekwalifiseer nie. Die inligting wat as uitsluitingskriteria gedien het, is van die ouers of voog wat die babas of kinders vergesel het, verkry. Die uitsluitingskriteria was as volg:

Babas en kinders wat:

- Die voorafgaande twee uur gebad, gestort of afgespons is.

- Die voorafgaande agt uur koorswerende medikasie ontvang het.

- 'n Infektiewe of inflammatoriese toestande in die oksel het.

- Binne die voorafgaande ses maande oorchirurgie ondergaan het.

- Enige obstruksie of misvorming van die eksterne oorkanaal, uitgesonderd normale wasafskeiding, het (Davis, 1993; Alexander et al., 1994).

Ingeligte toestemming is van ouers verkry, alvorens daar met die proef voortgegaan is. Proefpersone is gerusgestel indien hulle beangs of onseker voorgekom het. Die prosedure wat gebruik is, het geen risiko of gevaar vir proefpersone ingehou nie. Die protokol is goedgekeur deur die Etiekkomitee, Fakulteit Gesondheidswetenskappe, UOVS.

Die tydsduur van dataversameling per proefpersoon was ongeveer 15 minute, en die timpaniese membraan en aksillêre temperatuurmetings is gelyktydig by die proefpersoon gedoen. Alvorens daar met temperatuurmetings by proefpersone begin is, is die kamertemperatuur gemeet en die ondersoekkamer se temperatuur is aangepas indien dit te warm of te koud was.

Die instrumente wat gebruik is, is kwik-in-glas termometers en 'n Genius First Temp ototermometer.

Die aksillêre temeratuurmetings is as volg uitgevoer:

Die tyd van inplasing en verwydering van termometers is elke keer genoteer. Met die verwydering van die termometers is die lesings wat verkry is, genoteer. Die kwik-in-glas termometers ( $A$ en $B$ ) is elke keer voor inplasing afgeskud tot onder die laagste waarde.
- Die proefpersone is so ontklee dat slegs die romp en boonste ledemate ontbloot was. Die oksels is ondersoek en drooggemaak met 'n papierhanddoek.

- Termometer (A) se metingspunt is in die middel van die oksel geplaas. Die arm is stewig teenaan die metingspunt van die termometer $(A)$ vasgedruk en in posisie gehou deur die ouer of voog.

- Dieselfde prosedure is met die ander oksel gevolg en die termometers $(A)$ en $(B)$ is derhalwe gelyktydig in beide oksels geplaas.

- Na drie minute is die eerste termometer $(A)$ verwyder.

- Die termometer $(A)$ is weer volledig afgeskud, en in dieselfde oksel teruggeplaas en vir ses minute daar gehou.

- Die termometer in die ander oksel $(B)$ is na nege minute uit die oksel verwyder.

Die timpaniese membraam temperatuurmeting is as volg uitgevoer:

- Die ototermometer is in die kerntemperatuur modus gestel en gebruik, en die wegdoenbare plastiek bedekking is op die oorstuk geplaas.

- Die oorkanaal en timpaniese membraan is ondersoek vir patologie, oorwas en vreemde voorwerpe (Davis, 1993, Terndrup \& Milewski, 1991).

- Die oorstuk van die ototermometer is diep in die oorkanaal geplaas, sodat die oorkamer volledig afgeseël is, en die pinna is liggies infero-posteriorwaarts getrek (Pransky, 1991; Davis, 1993; Terndrup \& Milewski, 1991).

- Na twee sekondes is die skakelaar gedruk om die lesing te verkry wat op die skerm verskyn. Die lesing is genoteer en die ototermometer is uit die oorkanaal verwyder.

- Die prosedure is twee keer in elke oor herhaal en die hoogste lesingwaarde van elke oor, is vir die doeleindes van die studie gebruik.

Ten einde sydigheid en variasie so ver moontlik uit te skakel, is die ingeligte toestemmingsvorm aan die ouers in drie tale aangebied, een navorser het al die temperatuurmetings en dataversameling gedoen en derhalwe kon daar met groot omsigtigheid toegesien word dat dieselfde korrekte metode van temperatuurmeting by al die proefpersone gebruik is, die timpaniese membraan en aksillêre temperatuur is gelykertyd by die proefpersoon gemeet en die insluitings- en uitsluitingskriteria is streng nagekom.

Ten einde die betroubaarheid van die studie te verhoog is die ses kwik-in-glas termometers is in ' $n$ warmwaterbad getoets. Die ototermometer is vooraf gekalibreer om aan internasionale standaarde te voldoen (Davis, 1993; Stewart \& Webster, 1992).

Tien pasiënte is vooraf gebruik in ' $n$ loodsstudie om probleme te identifiseer en uit te stryk. Geen probleme is geïdentifiseer nie.

\section{Die statistiese ontleding het die volgende behels:}

Verskille is tussen alle metings bereken en opgesom deur gemiddeldes en $95 \%$ grense van ooreenstemming (Altman 1991). Deur die temperatuurklassifikasie van die timpaniese membraan meting as goue standaard te gebruik, is die sensitiwiteit (die vermoë om pireksie korrek te identifiseer) en die spesifisiteit (die vermoë om persone wat nie pireksies is nie, korrek te identifiseer) van die aksillêre temperatuurmetings bepaal. Verder is die aksillêre temperatuurmetings se positiewe voorspellingswaarde (persentasie proefpersone wat deur ' $n$ aksillêre temperatuurmeting as pireksies geklassifiseer is, en 
wat werklik pireksies is) en negatiewe voorspellingswaarde (persentasie proefpersone wat deur 'n aksillêre temperatuurmeting as nie pireksies geklassifiseer is nie, en wie se temperatuur wel normaal is) ook bereken.

Die normale reikwydte wat gebruik is vir timpaniese membraan temperatuur in die kern modus is $36^{\circ} \mathrm{C}$ tot $37,9^{\circ} \mathrm{C}$ (Stewart \& Webster, 1992). Die aksillêre temperatuur se reikwydtes is $35,5^{\circ} \mathrm{C}$ tot $37,5^{\circ} \mathrm{C}$ en $35,5^{\circ} \mathrm{C}$ tot $37,2^{\circ} \mathrm{C}$ (Ogrien, 1990 ; Morley, Hewson, Thornton \& Cole, 1992)

\section{Resultate en bespreking}

Van die 100 proefpersone wat aan die studie deelgeneem het, was $20 \%$ een jaar oud, $48 \%$ twee tot vyf jaar oud, $23 \%$ ses tot nege jaar oud, en $9 \% 10$ tot 12 jaar oud. Sewe en vyftig persent was vroulik en $43 \%$ manlik.

'n Verskeidenheid van 23 hoofdiagnoses het voorgekom. Drieen-sestig persent van die proefpersone het infeksies van die boonste lugweë, oor, neus, en keel gehad. Van die proefpersone het net ses ' $n$ regter otitis media gehad, een proefpersoon ' $n$ linker otitis media en 14 kinders het bilaterale otitis media gehad.

Die kamertemperatuur waar die navorsing uitgevoer is, het gewissel tussen $20^{\circ} \mathrm{C}$ en $24^{\circ} \mathrm{C}$. Die temperatuur was in $98 \%$ van die gevalle tussen $21^{\circ} \mathrm{C}$ en $23^{\circ} \mathrm{C}$. Dit dui op ' $\mathrm{n}$ onbeduidende klein variasie in kamertemperatuur. In $88 \%$ van die proefpersone stem die ore se klassifikasie

\section{TABEL 2: Vergelyking tussen linker- en regter timpaniese membraan temperatuur}

Regs

\begin{tabular}{|l|l|l|l|l|l|}
\hline \multirow{4}{*}{ FREKWENSIE } & $<\mathbf{3 6}$ & $\mathbf{3 6 - 3 7 , 9}$ & $\mathbf{3 8}+$ & Totaal \\
\cline { 2 - 6 } Links & $<\mathbf{3 6}$ & 1 & 1 & 0 & 2 \\
\cline { 2 - 6 } & $36-37,9$ & 0 & 76 & 6 & 82 \\
\hline $38+$ & 0 & 5 & 11 & 16 \\
\hline Totaal & 1 & 82 & 17 & 100 \\
\hline
\end{tabular}

Die 3 minute aksillêre temperatuurmetings neig om laer te wees as die 6 en 9 minuut waardes en die timpaniese membraanmeting, maar die 6 en 9 minuut aksillêre metings en die timpaniese membraan temperatuur verskil minder van mekaar (Tabel 3). Die aksillêre temperatuur neem toe van drie, na ses en na nege minute. Slegs $9 \%$ proefpersone het hul maksimum temperatuur bereik na drie minute, $25 \%$ na ses minute en $66 \%$ na nege minute.

(Slegs 99 proefpersone se data is in Tabel 4 weergegee, aangesien een proefpersoon se TMT $<36^{\circ} \mathrm{C}$ was, en al die aksillêre temperatuurmetings van die persoon normaal was.)

Die hoogste waarde vir spesifisiteit $\left(96,4 \%\right.$ ) (reikwydte $35,5^{\circ} \mathrm{C}$ tot $37,5^{\circ} \mathrm{C}$ ) is bevind wanneer aksillêre temperatuurmetings vir drie minute gemeet is (Tabel 4). Hierdie meting het ook die hoogste sensitiwiteit (68.75\%) van die drie metings as die reikwydte $35,5^{\circ} \mathrm{C}$ tot $37,5^{\circ} \mathrm{C}$ gebruik word. Die drie minute tydsduur vir aksillêre temperatuurmeting is dus baie betroubaar om proefpersone wat nie koorsig is nie te identifiseer indien die reikwydte $35,5^{\circ} \mathrm{C}$ tot $37,5^{\circ} \mathrm{C}$ gebruik is. Die relatief lae sensitiwiteit dui egter daarop dat nie alle kinders met pireksie korrek geklassifiseer word nie.

Indien die reikwydte $35,5^{\circ} \mathrm{C}$ tot $37,2^{\circ} \mathrm{C}$ gebruik word om normale aksillêre temperatuur te definieer, daal al drie aksillêre metings se spesifisiteit, maar die sensitiwiteit van die 6 en 9 minute metings verbeter aansienlik. Die 9 minute meting se sensitiwiteit is die hoogste, naamlik $\mathbf{8 7 . 5 \%}$

Alhoewel afsonderlike ouderdomsgroepe klein is en resultate dus met omsigtigheid benader moet word, is bevind dat die spesifisiteit en sensitiwiteit van die 3 minute meting deurgaans die hoogste is indien die reikwydte van $35,5^{\circ} \mathrm{C}$ tot $37,5^{\circ} \mathrm{C}$ as normaal beskou word. Indien die reikwydte van $35,5^{\circ} \mathrm{C}$ tot $37,2^{\circ} \mathrm{C}$ as normaal beskou word, het die 9 minute hoër sensitiwiteit maar laer spesifisiteit.

Indien die proefpersone met otitis media (21\%) buite berekening vir spesifisiteit en sensitiwiteit gelaat word, verander die persentasies met hoogstens 3\% (buiten die spesifisiteit van die 9 minute meting met die reikwydte $35,5^{\circ} \mathrm{C}$ tot $37,2^{\circ} \mathrm{C}$ waar die waarde daal van $54.2 \%$ tot $48.4 \%$ ). Hierdie bevinding stem ooreen met vorige studies wat gedoen is en toon aan dat otitis media nie ' $n$ beduidende invloed op die ooreen (Tabel 2). Die 95\% grense van ooreenstemming tussen die twee ore is $(-1 ; 1)$ en die gemiddelde verskil is $-0,01$. Aangesien die twee ore nie die identiese klassifikasie gee nie, is besluit om die gemiddelde timpaniese membraan temperatuur te bereken en as goue standaard te gebruik in die verdere ontledings.

TABEL 3: Verskille tussen temperatuurmetings

\begin{tabular}{|l|l|l|}
\hline VERSKILLE TUSSEN METING & Gemiddelde verskil & 95\% grense van ooreenstemming \\
\hline aksillêr 3-6 minute & $-0,25$ & $(-1: 1 ; 0,2)$ \\
\hline aksillêr 3-9 minute & $-0,35$ & $(-1 ; 0,25)$ \\
\hline aksillêr 6-9 minute & $-0,10$ & $(-0,7 ; 0,55)$ \\
\hline 3 minute - gemiddelde ore & $-0,25$ & $(-1,3 ; 0,78)$ \\
\hline 6 minute - gemiddelde ore & $-0,01$ & $(-1,0 ; 0,78)$ \\
\hline 9 minute - gemiddelde ore & $+0,10$ & $(-0,95 ; 1,08)$ \\
\hline linker-regteroor & $-0,01$ & $(-1: 1)$ \\
\hline
\end{tabular}

Volgens Tabel 5 het die 3 minute meting die hoogste p o s i t i e we voorspellingswaarde ( t e m perat u ur $\left.>37,5^{\circ} \mathrm{C}\right), 78,6 \%$, terwyl die positiewe voorspellingswaarde $\left(>37,2^{\circ} \mathrm{C}\right) \quad$ vir dieselfde meting $42,3 \%$ was. Dit blyk asof die laagste $p$ os i t i e w e voorspellingswaardes met metings van nege minute verkry 
Timpaniese membraan temperatuur is ' $n$ nuwe en dikwels onbekende metode wat baie voordele inhou vir die pasiënt en die gebruiker wat betref spoed, gerief, aanvaarbaarheid en akkuraatheid (Greenleaf \& Castle, 1972; Mayfield et al., 1984; Stewart \& Webster, 1992). Volgens studies wat gedoen is, is TMT 'n goeie voorspeller van kerntemperatuur en kan beskou word as die nuwe gove standaard.

aksillêre meting 3 minute

$68.75 \%$

$81.9 \%$

aksillêre meting 6 minute

$81.25 \%$

$68.7 \%$

aksillêre meting 9 minute

$87.50 \%$

$54.2 \%$

In die studie is ook bevind dat oorwas en otitis media geen beduidende effek het op die ooreenstemming tussen die metings nie, en dus waarskynlik

is, naamlik $38,5 \%\left(>37,5^{\circ} \mathrm{C}\right)$ en $26,9 \%\left(>37,2^{\circ} \mathrm{C}\right)$.

Wat die negatiewe voorspellingswaardes (reikwydte $35,5^{\circ} \mathrm{C}$ tot $37,5^{\circ} \mathrm{C}$ ) betref, is die hoogste waarde, $93 \%$, verkry by aksillêre temperatuur wat vir drie minute gemeet is. Dieselfde geld vir ' $n$ negatiewe voorspellingswaarde (reikwydte $35,5^{\circ} \mathrm{C}$ tot $37,2^{\circ} \mathrm{C}$ ) waar ' $n$ waarde van $93,8 \%$ verkry is, met aksillêre temperatuurmeting vir nege minute. Die negatiewe voorspellingswaardes was egter deurgaans hoog.

\section{Gevolgtrekkings en aanbevelings}

In hierdie studie is gevind dat die reikwydtes wat gebruik word, die sensitiwiteit en spesifisiteit van die metings beinvloed. Dit wil voorkom of dit beter is om die 9 minute meting met reikwydte van $35,5^{\circ} \mathrm{C}$ tot $37,2^{\circ} \mathrm{C}$ te gebruik om pireksie te identifiseer by die ouderdomsgroep een tot 12 jaar. Die bevinding stem ooreen met vorige studies wat gedoen is (Fraden, 1992; Erickson \& Woo, 1994).

Aksillêre temperatuur is nie 'n goeie voorspeller van kerntemperatuur nie en moet beskou word as perifere temperatuur en as ' $n$ hulpmiddel om kinders met pireksie te identifiseer. Hierdie bevinding stem ooreen met studies wat

\section{TABEL 5: Voorspellingswaardes van aksillêre temperatuurmeting voorspellingswaardes}

positiewe

aksillêr: normale reikwydte $35,5^{\circ} \mathrm{C}$ tot $37,5^{\circ} \mathrm{C}$

$\begin{array}{lll}\text { aksillêre meting } 3 \text { minute } & 78.6 \% & 93.0 \% \\ \text { aksillêre meting } 6 \text { minute } & 50 \% & 92.3 \% \\ \text { aksillêre meting } 9 \text { minute } & 38.5 \% & 90.5 \%\end{array}$

aksillêr: normale reikwydte $35,5^{\circ} \mathrm{C}$ tot $37,2^{\circ} \mathrm{C}$

aksillêre meting 3 minute

$42.3 \%$

$91.9 \%$

aksillêre meting 6 minute

$33.3 \%$

$93.4 \%$

aksillêre meting 9 minute
$26.9 \%$

$93.8 \%$ van geen kliniese belang by die timpaniese membraan temperatuurmeting is. Hierdie bevindinge stem ooreen met die van ander studies (Terndrup \& Wong, 1991; Muma et al., 1991; Kenney et al., 1990; Pransky, 1991; Freed \& Fraley, 1992; Chamberlain, Grandner, Rubinoff, Klein, Waisman \& Huey, 1991).

Daar is ook bevind dat die linker- en regteroor se metings van mekaar verskil, maar dat dit van min kliniese belang is. Hierdie bevinding stem ooreen met ander studies (Muma et al., 1991; Guthrie \& Kreuneve, 1992; Stewart \& Webster, 1992; Erickson \& Kirklin, 1993; Andrew \& Schuman, onbekend; Shinozaki, Deane \& Perkins, 1988).

\section{Aanbevelings}

Aksillêre temperatuurmeting is ' $n$ aanvaarbare metode om as sifting vir pireksie in ' $n$ noodgevalle- of buitepasiënt afdeling te gebruik, met die volgende voorbehoud:

- Die korrekte metingsmetode moet gebruik word.

- Die termometer moet verkieslik vir nege minute in die oksel gehou word om 'n betroubare lesing te verkry (Davis, 1993). Hierdie aanbeveling stem ooreen met die van studies wat aandui dat die temperatuur vir tot 11 minute in die oksel gemeet moet word (Haddock, Vincent \& Merrow, 1986; Kunnel et al., 1988; Mayfield et al., 1984; Anognostakis et al., 1993; Stephen \& Sexton, 1987; Schiffman, 1982).

- Die kind met ' $n$ aksillêre temperatuur bo $37,2^{\circ} \mathrm{C}$ moet as pireksies beskou en behandel word (Kresch, 1984; Morley et al., 1992).

- 'n Aksillêre temperatuur bo $37,2^{\circ} \mathrm{C}$ moet beskou word as gelykstaande aan ' $n$ kerntemperatuur van bo $37,9^{\circ} \mathrm{C}$ (TMT) (Stewart \& Webster, 1992) en as sodanig hanteer word (Morley et al., 1992)

- Die kwik-in-glastermometer moet gereeld getoets word om kallibrasiefoute uit te skakel omdat dit kan lei tot onakkurate lesings (Abbey et al., 1976).

Die ototermometer behoort meer dikwels in noodgevalleen buitepasiënt afdelings gebruik te word. Die grootste nadeel is dat die ototermometer duur is, maar as al die vooren nadele van die timpaniese- en aksillêre temperatuurmetingsmetode in ag geneem word, is dit definitief koste-effektief om 'n ototermometer te gebruik (Pransky, 1991; Chamberlain et al., 1991).

Daar word aanbeveel dat een modus (kerntemperatuur) in 
alle gevalle gebruik word, omdat die gebruik van kern, rektale en orale modus verwarring veroorsaak by die gebruiker (Rhoads \& Grandner, 1988; Davis, 1993).

' $n$ Verdere aanbeveling is dat ' $n$ ototermometer met ' $n$ kleiner oorstuk gebruik word by klein kinders en babas. Die Pedi-Q is 'n pediatriese weergawe van die ototemperatuur en pas gerieflik in klein kinders en babas se oorkanaal (Davis, 1993).

Die gebruiker van die ototermometer moet opleiding ontvang omdat die verkeerde tegniek kan lei tot onakkurate lesings (Shenep et al., 1991; Erickson \& Woo, 1994; Davis, 1993).

Manipulering van die oorkraakbeen kan lei tot hoër of meer akkurate lesings, en word aanbeveel (Shenep et al., 1991; Terndrup \& Rajk, 1992). Die pinna van die oorkraakbeen moet liggies na posterior getrek word om die oorkanaal meer reguit te maak.

Die meeste vervaardigers beveel aan dat twee of drie lesings geneem word (verkieslik in verskillende ore) en die hoogste lesing gebruik word. Die rede vir die metode is om tegniekfoute uit te skakel veral in kinders wat dikwels rondbeweeg, baie klein oorkanale het, asook in twyfelagtige gevalle waar die pasiënt warmer voel as die gemete temperatuur. Die metode gaan steeds minder as 20 sekondes neem en lei tot meer akkurate lesings.

\section{Bronnelys}

ABBEY, J.C., ANDERSON, A.S. \& CLOSE, E.L. 1976. How long is that thermometer accurate? American Journal of Nursing, $76: 1376$

ALEXANDER, D. \& KELLY, B. 1991. Responses of children, parents and nurses to tympanic thermometry in the pediatric office. Clinical Pediatrics, 30(4):53-56.

ALEXANDER, M.F., FAWCETT, J.N. \& RUNCIMAN, P.J. 1994 Nursing practice. Churchill Livingstone: Fawcett and Runciman

ALTMAN, DG. 1991. Practical statistics for medical research.Chapman \& Hall.

ANOGNOSTAKIS, D., MATSANIOTIS, N., GRAFAKOS, S. \& SARAFIDOU, E. 1993. Rectal, axillary temperature difference in febrile and afibrile infants and children. Clinical Pediatrics, $37: 768-772$

BARBER, N. \& KIMON, C.A. 1989. Reactions to tympanic temperature measurement in an ambulatory setting. Pediatric Nursing, 15:477-481.

BARTLETT, E.M. 1996. Temperature measurement: Why and how in intensive care. Intensive and Critical Care Nursing, 12:5054.

BLISS-HOLTZ, J. 1989. Comparison of rectal, axillary and inguinal temperature in full-term newborn infants. Nursing $R e$ search, 38:85-87.

BOYLAN, A. \& BROWN, P. 1985. Temperature. Nursing Times $81(16): 36-40$

BRINNEL, H., CABANA, C.M. 1989. Tympanic temperature is a core temperature in humans. Journal of Thermology Biology, 14:47-53.

CHAMBERLAIN, J.M., GRANDNER, J., RUBINOFF, J.L.
KLEIN, B.L., WAISMAN, Y. \& HUEY, M. 1991. Comparison of tympanic thermometer to rectal and oral thermometers in a pediatric emergency department. Clinical Pediatrics, . 30:(supplementary):24-29.

DAVIS, K. 1993. The accuracy of tympanic temperature measurements in children. Pediatric Nursing, 19:267-272.

ELOFF, M.J.F., MELER, R.S. \& MILLER, C. 1974. Temperature measurement in infants. Nursing Research, 23:457-460.

ERICKSON, A.S. \& MEYER, L.T. 1992. Accuracy of infrared ear thermometry and other methods in adults. American Medical Journal Critical Care, 3:40-54

ERICKSON, R.S. \& KIRKLIN, S.K. 1993. Comparison of tympanic based bladder, oral and axillary methods for core temperature measurement. Critical Care Medical, 2154.

ERICKSON, R.S. \& WOO, T.M. 1994. Accuracy of infrared ear thermometry and traditional temperature methods in young children. Heart and Lung, 23:181-195.

FRADEN, J. \& LACKEY, R.P. 1991. Estimation of body sites temperature from tympanic measurement. Clinical Pediatrics, 130(supplementary):65-70.

FRADEN, J. 1992. Medical infrared thermometry (review of modern techniques). In: Schooley, J.F. (ed.) Temperature its measurement and control in science and industry. Part 2 and New York: American Institute of Physics, 825-830.

FREED, G.L. \& FRALEY, J.E. 1992. Lack of agreement of tympanic membrane temperature assessments with conventional methods in a private practice setting. Journal of Pediatrics, 89:384-388.

GREENLEAF, J.F. \& CASTLE, B.L. 1972. External auditory canal temperature as an estimate of core temperature. Journal of Applied Physiology, 32:194-198

GUTHRIE, K.A. \& KREUNEVE, N.E. 1992. Tympanic-based core temperature measurement in relation to thermometer and technique. Masters thesis. Portland: Oregon Health Sciences University.

HADDOCK, B., VINCINT, P. \& MERROW, D. 1986. Axillary and rectal temperatures of fuil-term neonates: Are they different? Neonatal Network, 5:36-40.

HENRY, M \& ADAM, M.D. 1996. Fever and host responses. Pediatrics in Review.

KELLY, B. \& ALEXANDER, D. 1991. Effect of otites media on infrared tympanic thermometry. Clinical Pediatrics, . 30:(4):4648.

KENNEY, R.D., FORTENBERRY, J.D., SURRATT, S.S., RIBBECK, B.M. \& THOMAS, W.J. 1990. Evaluation of an infrared tympanic membrane thermometer in pediatric patient. Journal of Pediatrics, 85:854-858.

KRESCH, M.J. 1984. Axillary temperature as a screening test for fever in children. Journa/ of Pediatrics, 104:596-599.

KUNNEL, M.T., O'BRIEN, C., MUNRO, B.H. , MEDOFF \& COOPER, B. 1988. Comparison of rectal, femoral and axillary and skin to mattress temperatures in stable neonates. Nursing Research, 37:162-164, 189. 
MAYFIELD, S.T. BRATIA, J., NAKAMURAK, T., RIOS, G.R. \& BELL, E.F. 1984. Temperature measurement in term and preterm neonates. Journal of Pediatrics, 104:271-275.

MORLEY, C.J., HEWSON, P.H., THORNTON, A.J. \& COLE T.J. 1992. Axillary and rectal temperature measurement in infants. Archives of Disease in Childhood, 67:122-125.

MORLEY, C.J., THORNTON, A.J., COLE, T.J. \& HENSON, P. 1991. Baby check, a scoring system to grade the severity of acute systemic illness in babies under six months old. Archived Diseases in Children, 66:100-106.

MUMA, B.K., TRELOAR, D.J., WURMLINGER, K., PETERSON, E. \& VITAE, A. 1991. Comparison of rectal axillary and tympanic membrane temperatures in infants and young children. Annals Emerggency Medice, 20:41-44.

NIERMAN, D.M. 1991. Core temperature measurement in the intensive care unit. Critical Care Medical, 19(6):818-823.

OGRIEN, J.M. 1990. The inaccuracy of axillary temperatures measured with an electronic thermometer. American Medical Journal Diseases in Children, 149:109-11.

PRANSKY, S.M. 1991. The impact of technique and conditions of a tympanic membrane upon infrared tympanic thermometry. Clinical Pediatrics, 30 (4):50-52.

RHOADS, F.A. \& GRANDNER, J. 1988. Assessment of aural infrared sensor for body temperature measurement in children. Clinical Pediatrics, Febr., 29:112-115.

ROS, S.P. 1989. Evaluation of a tympanic membrane thermometer in an outpatients clinical setting. Annals Emergency Medicine, 18:1004-1006.

SCHIFFMAN, R.T. 1982. Temperature monitoring in the neonates: A comparison of axillary and rectal temperatures. Nursing Research, 3:(27):4-7.

SHENEP, J.L. , ADAIR, J.R. \& HUSHES, W.T. 1991. Infrared, thermistor and glass-mercury thermometry for measurement of body temperature in children with cancer. Clinical Pediatrics, . 30(supplementary):36-41.

SHINOZAKI, T., DEANE, R. \& PERKINS, F. 1988. Infrared tympanic thermometer: Evaluation of a new clinical thermometer. Critical Care Medicine, 16(2):148-150.

STEPHEN, S.B. \& SEXTON, P.R. 1987. Neonatal axillary temperatures: Increase in reading over time. Neonatal Network, $5: 25-28$.

STEWART, J.V. \& WEBSTER, D. 1992. Re-evaluation of the tympanic thermometer in the emergency department. Annals Emergency Medice, 21:158-161.

SUMMERS, S. 1991. Axillary, tympanic and esophageal temperature measurement. Journal of Post Anesthesia Nursing, $6: 420-425$.

TERNDRUP, T.E. \& MILEWSKI, A. 1991. The performance of two tympanic thermometers in a pediatric emergency department. Clinical Pediatrics, 30(supplementary):18-23.

TERNDRUP, T.E. \& RAJK, J. 1992. Impact of operator technique and device on infrared emission detection tympanic thermometry. Journal of Emergency Medice, 10:683-687.
TERNDRUP, T.E. \& WONG, A. 1991. Influence of otites media and the correlation between rectal and auditory canal temperature. American Medical Journal of Diseases in Children, 145:75-78.

TOMOTSU SHIWOZAKI, M.D., NOBERT, D. \& FREDERICK, M. 1988. Intrared tympanic thermometer evaluation of a new clinical thermometer. Critical Care Medicine.

WEISSE, M.E., REAGAN, M.S. , BAULE, L. \& FRANCE, N. 1991. Axillary vs rectal temperature in ambulatory and hospitalized children. Pediatric Infectious Disease, : 10 SUL, 1-542. 


\section{The experience of mothers caring for their teenage daughters' young children}

\author{
N Modungwa \\ M.Cur \\ Rand Afrikaans University
}

$\&$

M Poggenpoel

Ph.D

Rand Afrikaans University

$\&$

\author{
A Gmeiner \\ D.Cur
}

Rand Afrikaans University
"Teenage pregnancy and parenthood continue to haunt modern society into the 1990's. This is despite the availability of modern and effective technology for birth control."

\section{Abstract}

The purpose of this study was firstly to explore and describe the experiences of mothers who are looking after their teenage daughters' young children. Secondly, to formulate guidelines (based on the results obtained) for psychiatric nurses in assisting these mothers to mobilise resources in order to promote, maintain and restore their mental health as an integral part of health. An exploratory, descriptive, contextual and qualitative design was used and Guba's model for ensuring trustworthiness in qualitative research was applied. The phenomenological approach was used to collect and analyse data from a sample of seven respondents who were purposively selected. Three independent themes emerged from the analysis of results: Meaning of the parenting role, life-style changes and support systems. The results further show that for these mothers the problem of teenage pregnancy and parenthood ends up being their problem. Their experiences in looking after these babies, although sometimes fulfilling and meaningful, are most of the time stressful. This has implications on their mental health. Guidelines are recommended in order to facilitate these mothers to mobilise their resources for mental health.

\section{Opsomming}

Die doel van hierdie studie was eerstens om die belewenis van moeders wat die jong kinders van hul tienerjarige dogters oppas, te ondersoek en beskryf. Tweedens om riglyne te beskryf (gegrond op die verkreë bevindings) vir psigiatriese verpleegkundiges om hierdie moeders te help om bronne te mobiliseer ten einde hul geestesgesondheid te bevorder, te handhaaf en te herstel as ' $n$ integrale deel van gesondheid. ' $n$ Verkennende, beskrywende, kontekstuele en kwalitatiewe ontwerp is gebruik, en Guba se model om vertrouenswaardigheid in kwalitatiewe navorsing to verseker, is aangewend. 'n Fenomenologiese strategie is gebruik om data van ' $n$ steekproef van sewe respondente wat doelgerig gekies is, te versamel en te verwerk. Drie onhafhanklike temas het by die analise van gegewens na vore getree: Betekenis van die ouerskaprol, veranderinge in die lewenstyl en ondersteuningstelsels. Verder toon die resultate dat die probleem van tiener swangerskap en -ouerskap uiteindelik in die skoot van die tiener se moeder val. Hul belewenis van die versorging van hierdie babas, alhoewel soms vervullend, is meestal stresvol. Riglyne vir psigiatriese verpleegkundiges om hierdie moeders te help om hul bronne vir geestesgesondheid te mobiliseer word ten slotte beskryf.

\section{Introduction}

Teenage pregnancy and parenthood continue to haunt modern society into the 1990's. This is despite the availability of modern and effective technology for birth control.

While the situation applies to both developed and developing countries, it is the latter countries that are hit the hardest (Ojwang \& Maggwa, 1991:74). In African countries the rate of teenage pregnancy ranges between 10.5 to 51 per cent (Kooma in Sowetan, 1992:15). In South Africa there is also evidence that teenage pregnancy has taken on alarming proportions, particularly among coloured and Black communities (PrestonWhyte, 1991:7).

A lot has been written on the problems associated with early childbearing. One of these problems is that the teenage unable to play a parenting role. The onus then falls on the mother or mother figure to the teenage mother (particularly among Blacks) to take over this parenting role (Burman \& PrestonWhyte, 1992:231).

Research on the problems of teenage pregnancy and parenthood tended to focus solely on the teenage mother and her child(ren). The mother of the teenage mother is seldom focused on. This, despite her daily involvement in bringing up her teenage daughter's child(ren).

The result of this systematic omission by researchers and the popular media, is the absence of mothers of teenage mother, for one reason or another, is 